\title{
Tendências e Problemas Contemporâneos dos Direitos Fundamentais
}

\author{
OF. ex. Eernot Lippent \\ Professor Adjunto da Faculdade de Direito da \\ Universidade Federal do Rio Grande do Sul
}

A

s peculiaridades ontológicas do ser humano conferem-lhe a capacida de de organizar sua vida.

Desta capacidade decorre a "dignitas humana", que constitui no mundo moderno o conceito fundamental da relação do Homem com o Estado, impondo ao último limitações, conferindo ao primeiro direitos ou, como já enunciava o parágrafo 16 do Código Geral do Direito Civil da Áustria de 1811:

"Todo o ser humano é titular de direitos adquiridos pela nascimento, evidentes pela razão e, conseqüentemente, deve ser considerado pessoa."

Estes direitos são atualmente denominados "Direitos Humanos Fundamen tais", ou simplesmente "Direitos
Fundamentais"; no passado foram chamados de "Direitos do Homem". A atual Constituição Brasileira os denomina "Direitos e Garantias Fundamentais"2.

Visam estes direitos assegurar e garantir a cada ser humano, através do respectivo Estado, sua dignidade, sua igualdade, sua liberdade, seu direito à segurança física, à justiça social e à solidariedade.

O surgimento das liberdades públicas ocorre em três fases a saber:

$\mathrm{Na}$ Primeira Fase iniciada pela $\mathrm{Re}$ volução Americana ocorre a limitação do poder do estado através da institucionalização dos direitos individuais, também denominados modernamente de liberdades públicas.

1. "Jeder Mensch hat angeborene schon durch die Vernunft einleuchtende Rechte und ist daher als eine Person zu betrachten". ABGB-1811-Parágrafo 16.

2. "Não existe a respeito uma terminologia uniforme. Num recente debate na Suíça, objetivando a elaboração de um novo texto constitucional, foram apresentadas as seguintes sugestōes: Direitos Humanos, Direitos do Cidadão, Direitos Constitucionais Uniformes, Direitos Individuais, Liberdades Fundamentais, Direitos Fundamentais, Direito à Liberdade e, simplesmente, Direitos. 
Na Segunda Fase, iniciada logo após o fim da Primeira Guerra Mundial, surgem os direitos econômicos e sociais e na Terceira Fase, a partir de 1979 surgem os direitos de solidariedade humana ${ }^{3}$.

Tanto os direitos individuais, como também os direitos econômicos e sociais e os direitos de solidariedade tornaram-se direitos subjetivos públicos e, conseqüentemente, constituem obrigações do Estado; inicialmente obrigações de não fazer, e, posteriormente obrigações de fazer, de não fazer e de dar.

Por serem estes direitos precedentes ao Estado, não cabe a este concedê-los, pode a constituição declarar a dignidade humana, mas ela não os concede, apenas as reconhece.

A partir desta declaração a dignidade humana deixa de ser categoria metajurídica, filosófica ou teológica; ela é reconhecida, jurisdicizada, passa a ser um valor jurídico-constitucional com todas as conseqüências decorrentes.

Em outras palavras: Nem a constituição, nem a lei, nem qualquer outro texto jurídico conferem ao ser humano os direitos fundamentais, mas apenas os reconhecem, na medida do desenvolvimento humano, social, político e jurídico do respectivo Estado.

São "relembrados", pelas Constituições, os direitos fundamentais, base da dig-

nidade humana, através da expressa admissão da preexistência da mesma a quaisquer textos jurídicos. Cabe, conseqüentemente, ao Poder Público proteger os direitos humanos fundamentais; não apenas no relacionamento entre o Estado e o indivíduo, mas, também, no relacionamento dos indivíduos entre si.

Em outras palavras: Se a dignidade humana é inviolável, qualquer violação da mesma, por quem quer que seja, viola os direitos e garantias fundamentais.

Foram estes direitos declarados por terem sido reconhecidos pelo Estado, na medida de seu desenvolvimento social, político e jurídico. Não constituem, de outro lado, os direitos fundamentais atualmente declarados um "numerus clausus", conforme consta aliás, explicitamente, do parágrafo segundo do artigo 5 da Constituição Federal Brasileira.

Se os direitos fundamentais, na sua primeira fase, visam limitar o Estado, na segunda fase visam criar condições mínimas para assegurar a independência social do indivíduo. Vistos desta maneira, os direitos individuais são poderes de exigir ${ }^{4}$. Seu objeto é uma prestação positiva devida pelo Estado, a qual, se for impossível fática ou juridicamente, pode ser substituída por uma indenização em moeda, sendo aplicável por analogia nestes casos o disposto a respeito das indenizações na órbita do $\mathrm{Di}$ reito Civil.

3. "Os direitos de solidariedade foram apontados por Karel Vasak, em 1979, na abertura de cursos do Instituto Internacional dos Direitos do Homem, "apud" Manoel Gonçalves Ferreira Filho, Direitos Humanos Fundamentais, Editora Saraiva, 1995, p. 57.

4. "Boris Merkine - Guétzerich, "As Novas Tendências do Direito Constitucional", Cia. Ed. Nacional, 1933, p. 151, "apud" Manoel Gonçalves Ferreira Filho, "Direitos Humanos Fundamentais", Ed. Saraiva, 1995, p. 49.

Revista da Faculdade de Direito da UFRGS, v. 13, 1997
A violação dos Direitos Fundamentais poderá ocorrer tanto pelo Estado em relação ao ser humano como também por um ser humano em relação a outro ser humano, pois quem fere a dignidade humana de outro indivíduo fere os direitos fundamentais deste.

Cabe ao Poder Judiciário estabelecer as limitações necessárias à liberdade de agir do indivíduo, objetivando o resguardo e o fomento do convívio social, resguardados os limites, geralmente aceitos quanto à individualidade da pessoa, que sofre o dano decorrente ${ }^{5}$.

Examinando-se o desenvolvimento dos Direitos Humanos Fundamentais, cons tata-se a ausência de uma única fonte dos mesmos. Ao contrário, eles resultam da convergência dos mais diversos correntes sociais, religiosos, filosóficos, econômicos, políticos, ou, em outras palavras, da cultura ocidental. Quase sempre o seu surgimento é acompanhado do enfraquecimento do Poder Público, podendo-se indicar, como exemplo, as condições sociais quando da conquista pelos ingleses em 1215 dos direitos consubstanciados na Magna Charta Libertatis Populi Angelici, na "Bill of Rights" de 1628, na "Bill of Rights and Liberties of Subjects" de 1689, decorrentes da jurisprudência inglesa em geral quanto às "rules of law", do "due process of law", da "equal protection of the law", e da Revolução Americana e da Revolução Francesa.

Quanto à Revolução Americana, destacam-se a "Virginia Bill of Rights" de

5. "Handbuch des Staatsrechts - Josef Isensee und Paulo Kichhof, Band V, C.F. Müller, Juristischer Verlag - C.F. Müller Juristischer Verlag Heidelberg 1992, pág. 8 - Decisōes do Bundesverfassungsgerichtshof."

Revista da Faculdade de Direito da UFRGS, v. 13, 1997
1776, e os textos correspondentes de Pennsylvania, Maryland, Carolina do Norte, também de 1776, Massachusetts de 1780 e New Hamshire de 1784. Surgem com o advento da Revolução Americana e Francesa os direitos constitucionais de cada um, temente, aos Poderes Executivo, Legislativo e Judiciário.

Merece neste contexto ser lembrada a existência, mesmo antes da Revolução Americana e Francesa, de normas que "concediam" aos súditos determinados direitos, como na Inglaterra pela "Magna Charta" e as "bills" já anteriormente mencionadas. $\mathrm{Na}$ Alemanha os moradores das "Cidades $\mathrm{Li}$ vres", "Freien Reichstädte", e das "Cidades Hanseáticas" gozavam de certas garantias, mas todos estes direitos eram "concedidos" ou como escreveu Gottfried Dietze: "O rei declarava que não ia fazer".

Apenas com o advento da Constituição Americana e da Constituição Francesa surge o moderno conceito de Constituição, fundindo as antigas auto-delimitações impostas pelo Poder Público a si mesmo com os direitos humanos fundamentais "basis and foundation of Government" como a "Virginia Bill" os considerou.

Em decorrência destas alterações sociais o estado constitucionalmente determinado, torna-se o estado ideal cuja concretização se constitui numa missão permanente de seu povo. Demonstrou a história também que a divisão dos poderes do estado se constitui em uma exigência oponíveis ao Poder Público e, conseqüen- 
básica de seu funcionamento democrático, confirmando o magnífico acerto dos reda tores da Declaração de 1789 quando escreveram:

"Art. 16: Toute societé dans laquelle la garantie des droits n'est pas assurée ni la separation de pouvoir détrmineé, n'a point de Constitucion."

O conceito constitucional inicial, objetivando a organização do Estado sofre uma fusão com os direitos fundamentais da segunda e terceira fase. Desta fusão resulta o conceito do Estado moderno e as tendências dos direitos fundamentais. A organização do Estado e seu sistema de direitos fundamentais são unidos na respectiva constituição, a qual indica po sitivamente os fundamentos, valores e fi nalidades por ele adotados.

OEstado constitucionalmente determinado torna-se o Estado ideal cuja concretização se constitui numa missão permanente de seu povo. Os direitos humanos fundamentais influenciam a organização do moderno Estado constitucional como a exegese dos direitos fundamentais influenciam sua constituição.

Boris Merkine Guétzierich divulgando as "novas tendências do direito constitucional" nos anos vinte, exprime lapidarmente o núcleo da nova "concepção", nos seguintes termos:

"O Estado Moderno não pode contentar-se com o reconhecimento da independência jurídica do indivíduo; ele

deve ao mesmo tempo criar um mínimo

de condições jurídicas, que permitam assegurar a independência social do in dividuo."

Surge finalmente, em 1979, a terceira geração de direitos humanos, atinentes à qualidade de vida e à solidariedade humana $^{6}$.

São os seguintes os principais destes direitos: o direito à paz, o direito ao de senvolvimento, o direito ao meio ambiente e o direito ao patrimônio comum da humanidade, acrescentando alguns autores, ainda, o direito dos povos à auto de terminação e o direito à comunicação.

Quanto aos direitos de solidariedade, encontramos em nossa Constituição o artigo $4^{\circ}$, VI e VII, quanto à paz e à solução pacífica dos conflitos respectivamente.

Quanto ao direito ao desenvolvimento, a Constituição Federal é omissa constando o mesmo, entretanto, da "Declaração sobre o Direito ao Desenvolvimen to", editada pela ONU em 1986, quando essa declara constituir o mesmo um direito humano inalienável.

Quanto ao direito ao meio ambiente, temos o artigo 225 da Constituição Fe deral, cujo texto é o seguinte:

"Todos têm direito ao meio ambiente ecologicamente equilibrado, bem de uso comum do povo e essencial à sadia qualidade de vida, impondo-se ao Poder Público e à coletividade o dever de defendê-lo e preservá-lo para as presentes e futuras gerações."

Quanto ao direito à comunicação, temos o artigo 220 da Constituição Fede ral, nos seguintes termos:
Art. 220 - "A manifestação do pensamento, a criação, a expressão e a informação, sob qualquer forma, processo ou veículo não sofrerão qualquer restrição, observado o disposto nesta Constituição."

Quanto ao direito à informação, temos o disposto no artigo 5, XIV da Constituição Federal assim redigido:

XIV - "É assegurado a todos o acesso à informação e resguardado sigilo da fonte, quando necessário ao exercício profissional."

Quando à autodeterminação dos povos, dispõe o artigo 4, III da Conștituição Federal:

Art. 4ㅇ. "A República Federa tiva do Brasil rege-se nas suas relações internacionais pelos seguintes princípios:

$\cdots$ vos"

III - autodeterminação dos po

Examinando-se a história dos direitos fundamentais, constatamos, desde logo, uma larga expansão dos mesmos neste século, decorrente do surgimento dos direitos sociais e da solidariedade humana.

A concretização dos direitos fundamentais constitui-se na aplicação prática da teoria dos direitos fundamentais, consistindo essa numa compreensão orientada sistematicamente a respeito de seu caráter geral, seu direcionamento e sua extensão, o que nos obriga a pensar na função dos direitos fundamentais quanto à sua tipicidade.
Esta visão constitui um sistema de valores, objetivando a concretização dos direitos humanos fundamentais.

O objeto dos direitos fundamentais se alarga. Inicialmente restrito à proteção das liberdades públicas, passa o mesmo na segunda fase a incluir uma prestação positiva do Estado como o salário-desemprego, o serviço escolar ou educacional, os serviços médico hospitalares, de recreação e inúmeros outros, que variam de acordo com as condições de criatividade da respectiva sociedade e sua disponibilidade econômicafinanceira.

$\mathrm{Na}$ Alemanha, chegou-se através da jurisprudência à impenhorabilidade do segundo aparelho de televisão da família. Se a penhorabilidade do primeiro aparelho de televisão fere os direitos fundamentais do cidadão quanto a seu direito de informação, a impenhorabilidade do segundo aparelho da mesma família não me parece ser necessariamente uma imposição dos direitos humanos.

Repensando a matéria, constata-se que os direitos fundamentais formam quatro grupos compostos por:

1. liberdades públicas, que são os direitos de agir;

2. isonomia;

3. direitos econômicos e sociais, que se constituem em direitos de exigir, "fundados na cooperação e no socorro mútuo, próprio dos homens que vivem em sociedade"; e

4. pelos Direitos de Solidariedade Internacional, que correspondem à última geração dos direitos fundamentais, visando a paz, o desenvolvimento, a proteção ao

6. "Manoel Gonçalves Ferreira Filho, Direitos Humanos Fundamentais, obra já citada, p. 57." 
meio ambiente e ao patrimônio comum da humanidade e a autodeterminação dos povos.

A tendência dos direitos fundamentais consiste, como decorre do anteriormente exposto, numa expansão dos mesmos, resultando na democratização e no aumento da qualidade de vida, ou em outras palavras, no desenvolvimento do ser humano.

O aspecto negativo desta extensão dos direitos fundamentais consiste na sua banalização.

Deixaram os direitos fundamentais de ter uma incidência apenas nacional, tornando-se, ao menos parcialmente, normas internacionais, extraterritoriais. Os direitos fundamentais podem ter, conseqüentemente, uma fonte supranacional.

A concretização dos direitos fundamentais ainda não é universal. Ela é condicionada pelas convicções filosóficas, religiosas e econômicas dominantes em cada Estado, tendo, entretanto, uma aceitação generalizada nos países integrantes do mundo ocidental.

O crescimento do número dos direitos individuais ampliará o reconhecimento da "dignitas humana".

Os direitos humanos fundamentais devem ser protegidos tanto contra sua excessiva proliferação como contra a omissão do Estado quanto à sua concretização.

A elaboração adequada da doutrina e da jurisprudência, quanto aos Direitos Humanos Fundamentais, constitui-se em um dos maiores desafios jurídicos da humanidade em nossa época, pois "constitui-se na causa geral da liberdade".

\section{Bibliografia Atinente à Matéria}

BARBI, Celso Agrícola. Proteção processual dos direitos fundamentais. AJURIS, Porto Alegre, v. 43, p. 137 154, jul. 1988.

BRITO, Edvaldo. Limites da Revisão Constitucional. Porto Alegre: Sérgio Antônio Fabris, 1993, p. 32-35.

DALLARI, Dalmo de Abreu. Os direitos fundamentais na Constituição Brasileira. Revista da Faculdade de Direito, São Paulo, v. 88, p. 421-496, 1993.

FERREIRA FILHO, Manoel Gonçalves. Curso de Direito Constitucional. 21 ed. São Paulo: Saraiva, 1994. 322 p.

Liberdades públicas. São Paulo: Saraiva, $1978.537 \mathrm{p}$.

. Direitos humanos fundamentais. São Paulo: Saraiva, 1995. 189 p.

FERREIRA, Wolgran Junqueira. Direitos $e$ garantias individuais; comentários ao art. 5 da CF/88. Bauru, SP. EDIPRO. $1997.717 \mathrm{p}$.

GUERRA FILHO, Willis Santiago. Direitos Fundamentais: teoria e realidade normativa. Revista dos Tribunais, São Paulo, v. 113, p. 45-52, mar. 1995.

ISENSEE, Josef, KIRSCHOF, Paul. Handbuch des Staatsrechts der . Bundesrepublik Deutschland. Heidelberg: C.F. Müller Juristischer Verlag, 1992. 5 Vol.

LEITE, Luciano Ferreira. Aplicabilidade imediata dos direitos e garantias individuais da Nova Constituição. Revista dos Tribunais, São Paulo, v. 635, p. 14 18 , set. 1988 .
MAGALHÃES, José Luiz Quadros. As garantias dos direitos fundamentais. Revista de Informação Legislativa, Brasília, v. 122, p. 41-46, maio/jul. 1994.

MARINHO, Josaphat. Direitos e garantias fundamentais. Revista de Informação Legislativa, Brasília, v. 127, p. 5-12, jul./ set. 1995.

MARQUES, Floriano Azevedo. O choque de direitos e o dever de tolerância: os direitos fundamentais no limiar do século XXI. Cadernos de Direito Constitucional e Ciência Política, v. 9, p. 35-41, 1994.

MARQUES NETO, Floriano Azevedo. Conceito e evolução dos direitos fundamentais. Cadernos de Direito Constitucional e Ciência Política, v. 5, p. 54-61, 1993.

MENDES, Gilmar Ferreira. Colisão de direitos fundamentais: liberdade de expressão e de comunicação e direito à honra e à imagem. Cadernos de Direito Tributário e Finanças Públicas, São Paulo, v. 5, p. 16-20, out./dez. 1993.

MIRANDA, Jorge. Os direitos fundamentais, sua dimensão individual e social. Cadernos de Direito Constitucional e $\mathrm{Ci}$ ência Política, v. 1, p. 198-208, 1992.

NORONHA, Carlos Silveira. Liberdades públicas; uma breve visão político-filosófica. Revista Forense, v. 328. p.3136.

ROLIM, João Dácio. Os direitos fundamentais e o fato gerador de obrigação tributária ... Cadernos de Direito Tributário e Finanças Públicas, São Paulo, v. 12, p. $80-93$, jul./set. 1995
SARLET, Ingo Wolfgang. Valor da alçada e limitação de acesso ao duplo grau de jurisdição ... AJURIS, Porto Alegre, v. 66, p. 85-127, mar. 1996.

SILVA, Guilherme Amorim Campos da, TAVARES, André Ramos. Extensão da aras popular enquanto ... Cadernos de Direito Constitucional e Ciência Política, v. 11, p. 106, 1995.

SILVA, José Afonso da. Curso e Direito Constitucional Positivo. 10 ed. São Paulo: Malheiros, 1994.820 p.

SILVA FILHO, Derly Barreto e. Destinação e utilidade do mandado de injunção Revista dos Tribunais, São Paulo, v. 613, p. 42-46, nov. 1991

SOUZA, Nelson Oscar de. Manual de Direito Constitucional. Rio de Janeiro: Forense, 1994.338 p.

TÁCITO, Caio. Proteção dos direitos fundamentais. Cadernos de Direito Tributário e Finanças Públicas, São Paulo, v. 6, p. 7-14, jan./mar. 1994.

TUCCI, Rogério Lauria. Constituição de 1988 e Processo. São Paulo: Saraiva, 1988. p. 136-141

VIDIGAL, Geraldo de Camargo. Direitos e garantias fundamentais na Revisão Constitucional. Cadernos de Direito Tributário e Finanças Públicas, São Paulo, v. 6, p. 11-14, jan./mar. 1994.

ZAVASCKI, Teori Albino. Antecipação da tutela e colisão de direitos fundamentais. AJURIS, Porto Alegre, v. 64, p. 395-417, jul. 1995. 